\title{
An Electron Microscope Study of Maturation and Germination of Sporangiospores of Two Species of Rhizopus
}

\author{
LILIAN E. HAWKER AND PATRICIA McV. ABBOTT \\ Department of Botany, University of Bristol
}

(Received 18 February 1963)

\begin{abstract}
SUMMARY
Immature sporangiospores of Rhizopus nigricans and $R$. sexualis were relatively thin-walled, although thickened longitudinal ridges were already discernible. The position of the nuclei suggested that they had recently divided; the mitochondria were globose and similar to those of vegetative hyphae; the protoplast was surrounded by a thin plasmalemma and contained numerous food globules. The endoplasmic reticulum was sparse. Mature spores had a thick wall of reticulate structure and contained large contorted mitochondria. The first visible stage in germination was the formation of an inner cell wall of tangential elements resembling that of the vegetative hyphae and contrasting with the original spore wall. The mitochondria increased in number, probably by division of the large contorted ones of the dormant spore, and were again regularly globose. The original spore wall became considerably stretched and finally ruptured to allow the germ tube enveloped in the newly formed elastic inner wall to emerge.
\end{abstract}

\section{INTRODUCTION}

Electron-micrographs of sporangiospores of Rhizopus sexualis (Smith) Callen and $\boldsymbol{R}$. nigricans Ehrenb. revealed hitherto undetected changes in fine structure during maturation and germination.

\section{METHODS}

The material was fixed with Luft's permanganate (Luft, 1956) or with permanganate followed by osmium tetroxide as previously described (Hawker \& Abbott, 1963). The fixed material was embedded in araldite, sectioned with a glass knife on a Huxley ultra-microtome (Cambridge Instrutment Co.) and examined with a Philips EM 200 electron microscope, as in earlier work.

\section{RESULTS \\ Maturation of sporangiospores}

Immature spores (Pl. 1, fig. 1), presumably released by rupture of the sporangial wall during fixation, were often slightly flattened at one side, probably where they had been in contact with other spores. The spore wall was relatively thin and consisted of a single layer, but already showed the thickening which would later have become the characteristic longitudinal ridges of the mature spore. These thickenings were blackish in osmic-fixed material, indicating the presence of lipid material. The plasmalemma was thin and in close contact with the wall. The endoplasmic reti- 
culum was sparse with a few scattered cisternae, thus resembling that of the vegetative hyphae (Hawker \& Abbott, 1963). Typical nuclei, mitochondria, and numerous reserve food globules, many of which were of a fatty nature, were present. The nuclei in these immature spores were more or less centrally placed in a group of two or four, suggesting recent division. The nuclear membrane and the nucleolus were similar to those of young vegetative hyphae. The mitochondria were globose or ovoid with a regular outline and the inner membrane was infolded to give groups of roughly parallel plate-like cristae, as in young vegetative hyphae.

During maturation (Pl. 1, fig. 2) the spore outline became symmetrical, finally becoming more or less lemon-shaped and slightly flattened longitudinally. The longitudinally ridged wall became very thick $(0 \cdot 3-0 \cdot 6 \mu)$ and consisted of apparently regularly arranged elements enveloped in an amorphous mass of fatty material (staining black with osmium tetroxide; Pl. 2, fig. 4). At this stage there were no tangentially arranged elongated elements such as those which make up the wall of the vegetative hypha. The plasmalemma remained thin, closely lining the wall. The nuclei had moved apart. Complete sets of serial sections were not obtained for any one spore but a study of a large number of sections suggested that the usual number of nuclei was four and that these were arranged equatorially. The number, size and distribution of storage granules and the scattered cisternae showed no significant change. The most striking change, apart from the thickening of the wall, was in the shape and size of the mitochondria (Pl. 2, figs. 5, 6). These had enlarged, had become convoluted and now contained a complex system of closely packed cristae. The contorted shape of the mitochondria was not due to shrinkage during fixation since their actual size had increased in comparison with those of immature spores. Moreover, the nuclei and plasmalemma were neither shrunken nor contorted, indicating satisfactory fixation.

\section{Germination of sporangiospores}

Spores were suspended in water; they germinated after $3 \mathrm{hr}$. or more and were fixed after 5-6 hr. The first visible structural change was the laying down of a thin inner wall ( $\mathrm{Pl} .2$, figs. 3, 4). This consisted of tangentially arranged elements and thus resembled the wall of the vegetative hypha (Hawker \& Abbott, 1963) but was strikingly different from the original spore wall. During these early stages of germination the spore enlarged and the wall became stretched, as indicated by the increasing distance between the wall ridges. The mitochondria became more numerous, smaller and regular in outline (Pl. 2, fig. 7). It must be assumed that the large irregularly-shaped mitochondria of the mature spore had undergone fission to give an increased number of these organelles in the germinating spore. In many spores, the nuclei and mitochondria were more densely congregated at one side, presumably at the point where the germ tube was about to emerge.

When germination took place the original spore wall, now much stretched, broke and the germ tube emerged, enclosed by the newly-formed elastic inner wall (Pl. 3, figs. $8,9,10)$. The contents of the spore flowed into the germ tube, both nuclei and mitochondria becoming elongated and orientated in the direction of flow. Flow lines, or perhaps thin membranes, could be traced in the endoplasm. Just behind the tip of the germ tube these resembled the membranes already reported in vegetative hyphae (Hawker \& Abbott, 1963). The extreme tips of the germ tubes contained 
mitochondria; the nuclei, as in vegetative hyphae, were some distance behind the tip (Pl. 3, fig. 11). Vacuoles developed in the part of the spore distant from the germ tube.

\section{DISCUSSION}

The most striking new facts about the maturation and germination of Rhizopus spores shown by the present work are the rapid formation of an inner wall, of a type radically different from the original spore wall, immediately after the spores are suspended in water, and the changes in the mitochondria. The tangential arrangement of the elements of the new wall is likely to give greater elasticity in a direction parallel to the surface than would the reticulate structure of the old wall. Nevertheless the latter does stretch considerably before it becomes ruptured to allow the emergence of the germ tube. During this stretching the original wall becomes correspondingly thinner and the ridges less marked. The shape of the spore becomes altered owing to the slight plasticity of the original wall, so that there is no constriction of the emerging germ tube. Under the light microscope the spore wall appears to be entire and to continue around the germ tube. The electron microscope shows conclusively that this is not so and reveals the rapid formation of an elastic inner wall as one of the first stages in germination. At the point of emergence of the germ tube the original cell wall shows a clean break.

Multiplication of mitochondria by division of old ones rather than by de novo formation was shown by Manton (1961) to occur in the liverwort Anthoceros laevis and in the Chrysophycean flagellate Chrysochromulina brevifilum. Hashimoto, Conti \& Naylor (1958), however, claimed that the mitochondria in ascospores of Saccharomyces cerevisiae disappeared during dormancy and that on germination they were formed anew. An examination of their photographs, however, suggests that the material was incompletely fixed, since few details of internal structure can be seen. We had considerable difficulty in securing proper fixation of the thick walled Rhizopus spores and concluded that fixation was best with slightly damaged spores. Only spores which showed well-fixed contents were considered in the present study. Mitochondria could not be distinguished in poorly fixed spores.

Thanks are due to the Department of Physics, University of Bristol, for allowing us to use the electron microscope. We are also indebted to the D.S.I.R. for a grant in aid of this investigation.

\section{REFERENCES}

Hashimoto, T., Conti, S. F. \& Naylor, H. B. (1958). Fine structure of micro-organisms. III. Electron microscopy of resting and germinating ascospores of Saccharomyces cerevisiae. J. Bact. 70, 406.

Hawker, L. E. \& Aвbott, P. McV. (1963). Fine structure of vegetative hyphae of Rhizopus. J. gen. Microbiol. 30, 401.

Luft, J. H. (1956). Permanganate-a new fixative for electron microscopy. J. biophys. biochem. Cytol. 2, 799.

Manton, I. (1961). Some problems of mitochondrial growth. J. exp. Bot. $12,421$. 


\section{EXPLANATION OF PLATES}

Plate 1. Rhizopus nigricans

Fig. 1. Approximately transverse section of an immature sporangiospore, showing relatively thin, ridged spore wall $(S W)$; plasmalemma $(P)$; four nuclei $(N)$ the relative positions of which suggest that they originated from a single nucleus and had just completed a second division; mitochondria $(\boldsymbol{M})$ with entire outlines and well-defined cristae; miscellaneous food globules $(\boldsymbol{F})$; and sparse endoplasmic reticulum $(\boldsymbol{R})$.

Fig. 2. Oblique section through mature sporangiospore; showing thick spore wall surrounded by black amorphous layer $(B)$; plasmalemma; three nuclei; large complex lobed mitochondria; food globules; and endoplasmic reticulum. Other lettering as in fig. 1.

\section{Plate 2. R. nigricans. Lettering as in Pl. 1}

Fig. 3. Approximately transverse section through sporangiospore soaked in water for 5 hr.; showing development of inner wall $(I W)$ and apparent fission of lobed mitochondria (e.g. $M_{1}$ and $M_{2}$ ) to form more numerous, smaller ones of more regular shape.

Fig. 4. Section through part of wall of a spore at same stage as that shown in fig. 3. Note reticulate arrangement of elements in original spore wall and presence of newly formed inner wall consisting of tangentially arranged elements.

Fig. 5. Mitochondria from young spore (note thin spore wall on left) showing incipient lobing.

Fig. 6. Two complex lobed mitochondria and part of a third from a mature spore. Enlarged from area indicated by arrow in fig. 2. Note complex groups of cristae.

Fig. 7. Mitochondria from germinating spore. Note relatively small size, regular outline and groups of parallel cristae.

Plate 3. Rhizopus sexualis. Lettering as in Pls. 1 and 2

Fig. 8. Oblique section through germinating sporangiospore (soaked in water for 5 hr. before fixation); showing germ tube $(G T)$, enclosed by wall continuous with inner wall of spore, emerging through clean break $(X)$ in outer space wall. Note enlongated mitochondria and nuclei flowing towards and into germ tube, and lines of flow, or possibly 'cortical' membranes, $(C)$ in endoplasm near base of germ tube.

Fig. 9. Part of fig. 8 enlarged to show broken spore wall at points of emergence of germ tube.

Fig. 10. Approximately median section through emerging germ tube of another spore at same stage as that shown in figs. 8 and 9 ; showing clean break of original spore wall. Part of spore concealed by grid.

Fig. 11. Longitudinal section of germ tube at a slightly older stage than those of figs. 8-10. Spore concealed by grid. Note presence of mitochondria and absence of nuclei at extreme tip, presence of nuclei further back, and flow lines or 'cortical' membranes in endoplasm. 

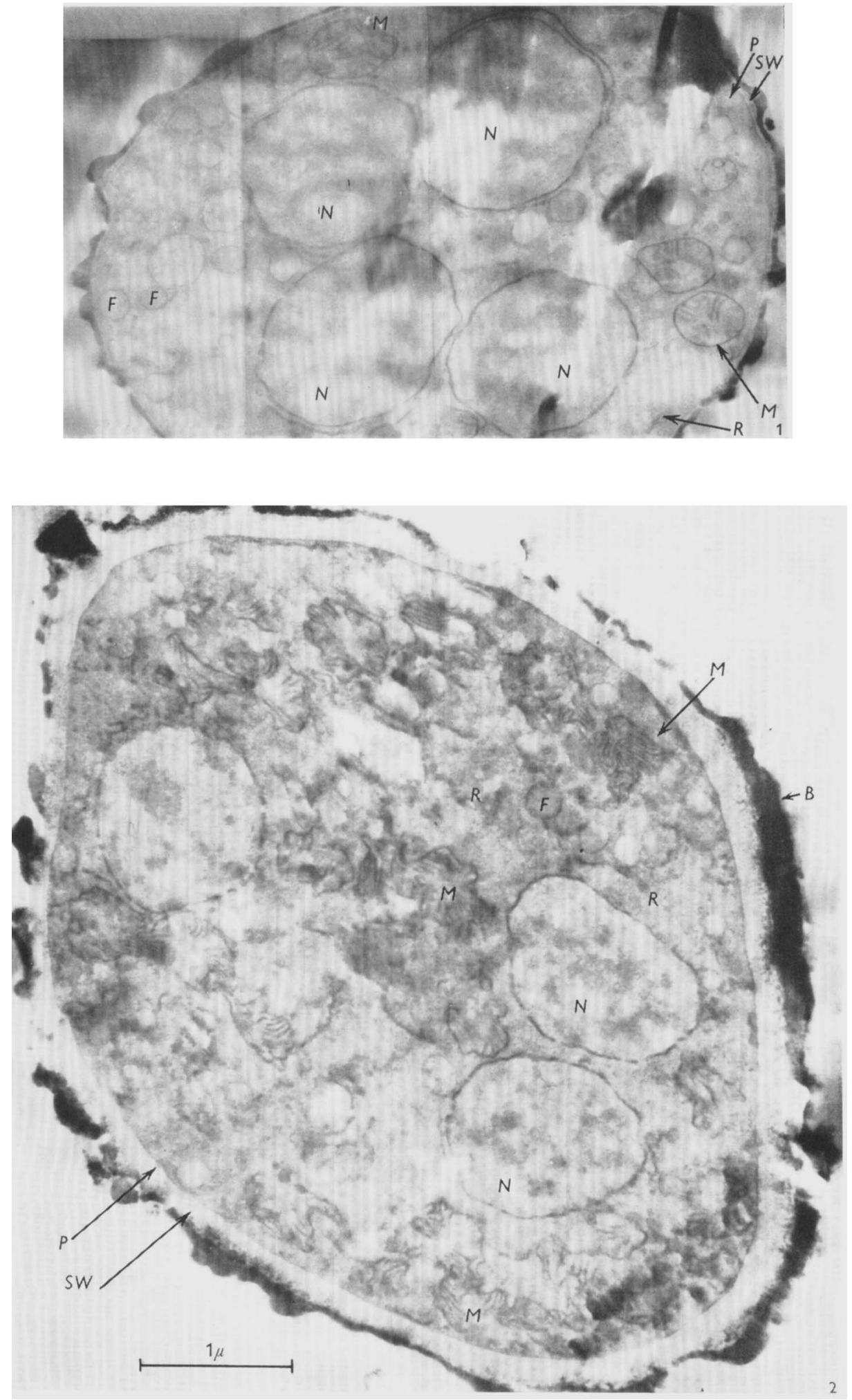


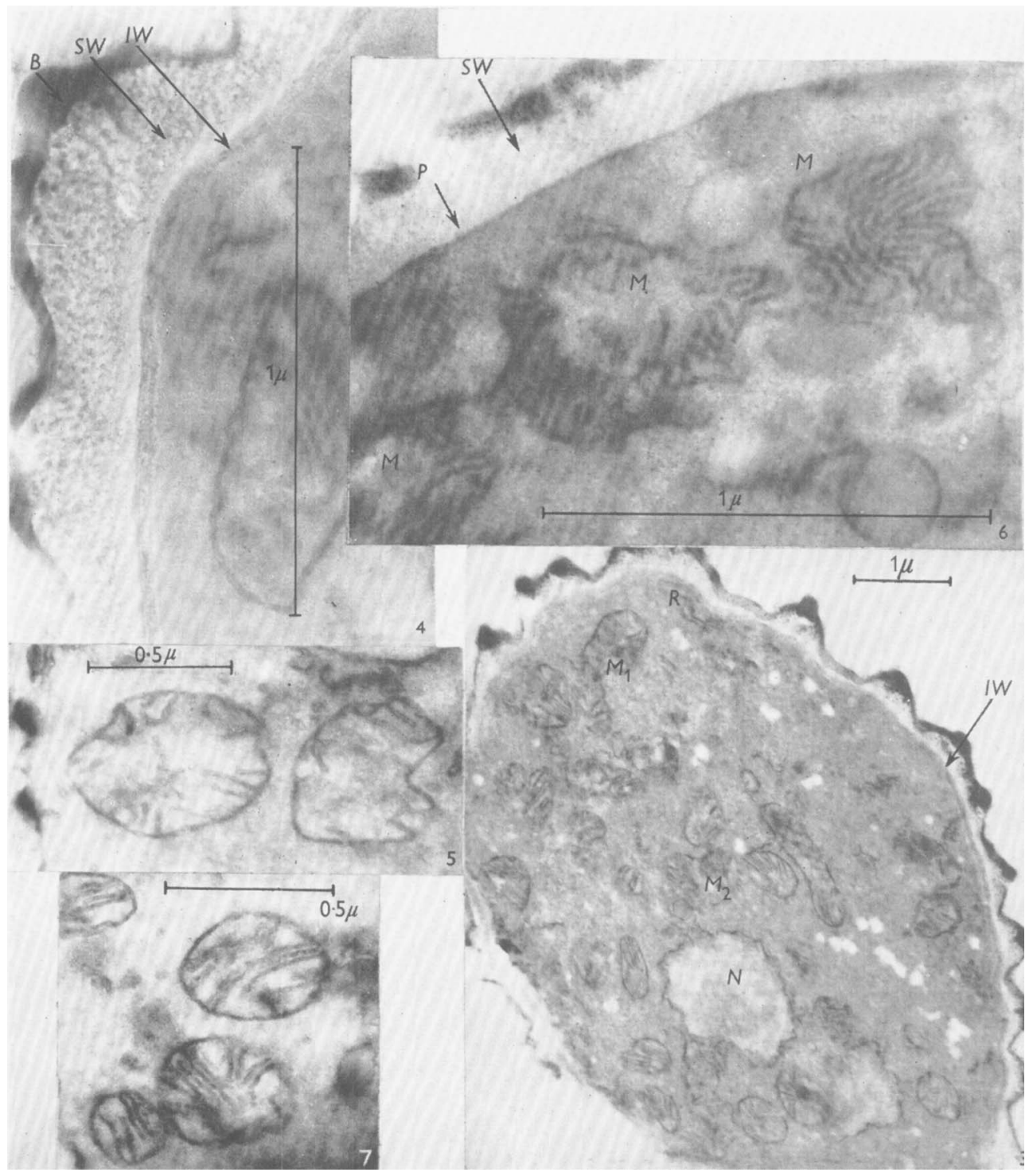




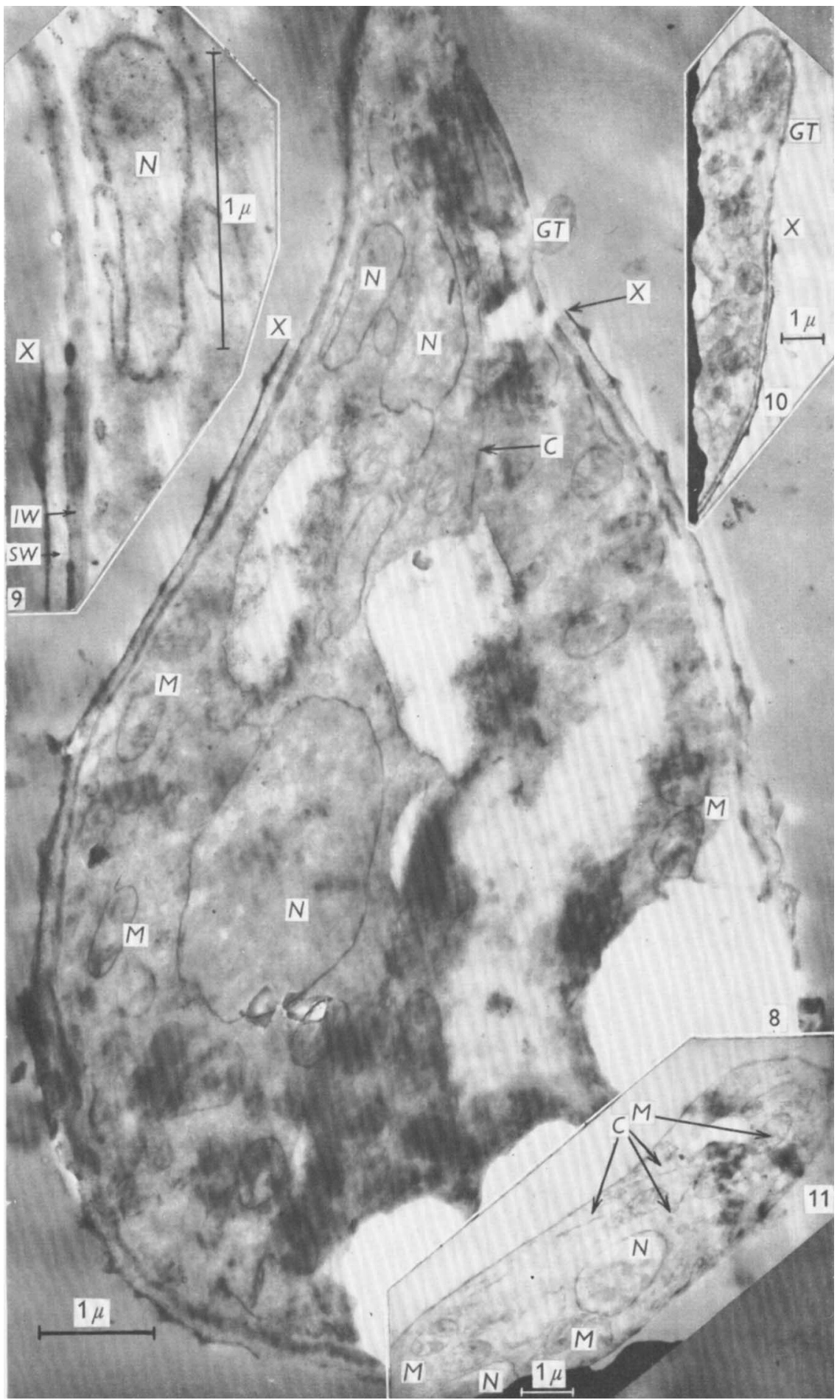

L. E. HAWKER AND P. MCV. ABBO'l'T 